\title{
Study on Pharmacognosy Curricula in UAE B. Pharm Programmes and Possible Implications
}

\author{
I.M. Abu-Al-Futuh*
}

\section{I.M. Abu-Al-Futuh*}

College of Pharmacy and Health Sciences, University of Science and Technology of Fujairah, PO. Box 2202 Fujairah, UAE.

\section{Correspondence}

I.M. Abu-Al-Futuh

College of Pharmacy and Health Sciences, University of Science and Technology of

Fujairah, PO. Box 2202 Fujairah, UAE.

Phone no: +971506733656;

Fax: +97192227644,

E-mail: e.shanda|@ustf.ac.ae

History

- Submission Date: 12-02-2020;

- Review completed: 21-02-2020;

- Accepted Date: 10-03-2020

\section{DOI : 10.5530/pj.2020.12.74}

Article Available online

http://www.phcogj.com/v12/i3

Copyright

(C) 2020 Phcogj.Com. This is an openaccess article distributed under the terms of the Creative Commons Attribution 4.0 International license.

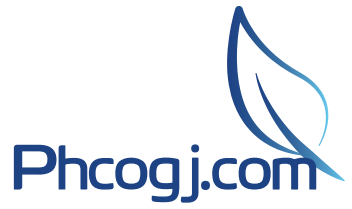

\begin{abstract}
Introduction: The current Pharmacy Curricula development initiatives in developing countries are focused on the expansion of courses in Patient-oriented Pharmacy Education. This resulted in the decrease of credit hours allotted to Pharmacognosy curricula. Methods: The current curricula for the Bachelor of Pharmacy (B Pharm) programme of universities in the United Arab Emirates (UAE) were studied. The curricula stated in the Study-Plans of these universities were divided into eight divisions based on the specialty of courses. The divisions: Pharmaceutics; Pharmaceutical Chemistry; Pharmacology; Pharmacognosy; Patient-oriented Courses; Training; Biomedical and University Requirements. Study-Plans data were obtained from related universities' official websites. The percentage analysis of credit hours allotted to each division was calculated. In addition to UAE, B Pharm programmes of representative universities from Africa and the Middle East were also studied for comparison. Results: Results obtained from UAE Universities show that Pharmacognosy division has (4.7\%); Pharmaceutics (15\%); Pharmaceutical Chemistry (14.4\%); Pharmacology (9.7\%); Patient-oriented Courses (18.8\%); Training (11.5\%); Biomedical courses (10.8\%) and University Requirements (15.7\%). Our analysis of study-plans of other representative universities from Middle East $(8.6 \%)$ and Africa (8.9\%) demonstrated a higher percentage for Pharmacognosy compared to UAE $(4.7 \%)$ Universities. Conclusion: The inadequate credit hours allotted to Pharmacognosy division may have adverse implications on Drug Industry, Patient Health Care and Herbalism. Recommendations are given on how to amend this inadequacy in Pharmacognosy curricula. Key words: Pharmacognosy, Drug Discovery, B. Pharm. Curricula.
\end{abstract}

\section{INTRODUCTION}

Pharmacognosy is the science which studies crude drugs from plants, animal and mineral origin. Such drugs are prepared as tinctures, teas, poultices, powders, and other herbal formulations. In the past Pharmacognosy education included identification and quality control of crude drugs based on macroscopic and microscopic examination. ${ }^{1}$ Recently, Pharmacognosy included identification, isolation and biological activities of natural active constituents from crude drugs. New courses related to ethnobotany, ethnomedicine, and ethnopharmacology were included. Though the word Pharmacognosy rarely appears in the Pharmacy curricula of the UK and USA, some of the contents of Pharmacognosy are present in other terminologies such as drug discovery, natural products, medicinal plants, herbal therapy, phytotherapy, natural medicines, and phytopharmaceuticals. The importance of Pharmacognosy is increasing in countries such as Brazil, China, and India. ${ }^{1}$

Active constituents from medicinal plants lead to new drug discovery. ${ }^{2}$ Research in many isolated active constituents from medicinal plants has resulted in compounds for the treatment of cancer, bacterial and viral infections and immunity disorders. In most cases, the discovery of new active constituents from medicinal plants leads to a better understanding of pathways in diseases, ${ }^{3}$ as well as drug discovery.

Herbalism is the use of different morphological parts from crude plant materials, either whole or reduced in size, to promote health. Herbalism refers to the application of Pharmacognosy knowledge to promote health by the use of crude medicinal plants. This practice was the ancient treatment for diseases 100 years ago. Nowadays, about $80 \%$ of the world population depends on herbal medicine. In 2008 the world market for herbal medicine was about USD 83 billion. It increased to 100 billion in 2013 and is continuously increasing. ${ }^{4}$

In the past, pharmacognosy represented a major part of B. Pharm Curricula in Universities. This was due to the fact that Pharmacognosy was the basic science from which other Pharmaceutical Sciences were developed.

The current Pharmacy Curricula development initiatives in developing countries are focused on the compatibility of B. Pharm. programmes in those countries with curricula of Pharm D. and M. Pharm programmes in the USA and Europe, respectively. The fundamental reason for these initiatives was the expansion of courses in Patient-oriented Pharmacy. This necessitated the introduction of more courses related to clinical pharmacy. ${ }^{5}$ Yet, it was reported that an ideal clinical pharmacy set up in the health care systems of these developing countries is still

Cite this article: Abu-AI-Futuh IM. Study on Pharmacognosy Curricula in UAE B. Pharm Programmes and Possible Implications. Pharmacogn J. 2020;12(3):478-84. 
under developed. ${ }^{6}$ Shandal and co-workers, ${ }^{7}$ reported on the need of a balanced curricula between patient - oriented courses and other pharmaceutical sciences. To our knowledge no other workers reported on the possible implications of pharmacognosy curricula in UAE, Africa and Middle east.

This study was directed mainly to UAE Universities offering B. Pharm programmes. Representative Universities from other regions offering B. Pharm programmes were also included in the study. The objective of this study is to reflect the effect of insufficient Pharmacognosy curricula at the university level and its implication on Drug production and Discovery, Health Care System, and Herbalism. Recommendations to overcome the adverse effects resulting from this impact are given.

\section{METHODS}

\section{Data collection}

The source of data for this study was collected from official websites of thirteen (13) different universities offering B. Pharm programmes. . $^{820}$ Among 13 universities, 6 universities from UAE, 3 from Africa and 4 from the Middle East. Study plans representing the curricula of B. Pharm programmes for these universities were subjected to this study.

\section{Divisions of the study plan}

Each Study Plan is divided into eight divisions. Each division includes the total credit hours for courses belonging to the same specialty. Courses included under each division (Table 1) are not necessarily all courses included in the studied Study Plans, but represents the most common courses in these Study Plans.

\section{Data analysis of B. Pharm curricula}

The data analysis of B. Pharm. Curricula were achieved by summing the credit hours allotted for all courses related to each division of the study plan, then the percentage of each division from total credit hours of the study plan was calculated (Table 2).

\section{Analysis of B. Pharm curricula in UAE}

The study plans of six universities from UAE offering B. Pharm programme were analyzed according to data analysis of B. Pharm. Curricula. The B.Pharm Study duration in these universities is four years and range from 150-170 credit hours (Table 2).

\section{Analysis of B. Pharm curricula in Africa}

The study plans of three universities from Africa offering B. Pharm programme were analyzed according to data analysis of B. Pharm. Curricula described at the beginning of the Methodology. In these universities, study duration is five years and range from 188-310 credit hours (Table 3).

\section{Analysis of B. Pharm curricula in the middle East}

The study plans of four universities from the Middle East offering B. Pharm programme were analyzed according to data analysis of B. Pharm. Curricula described at the beginning of the Methodology. In

\section{Table 1: Divisions of Study Plan.}

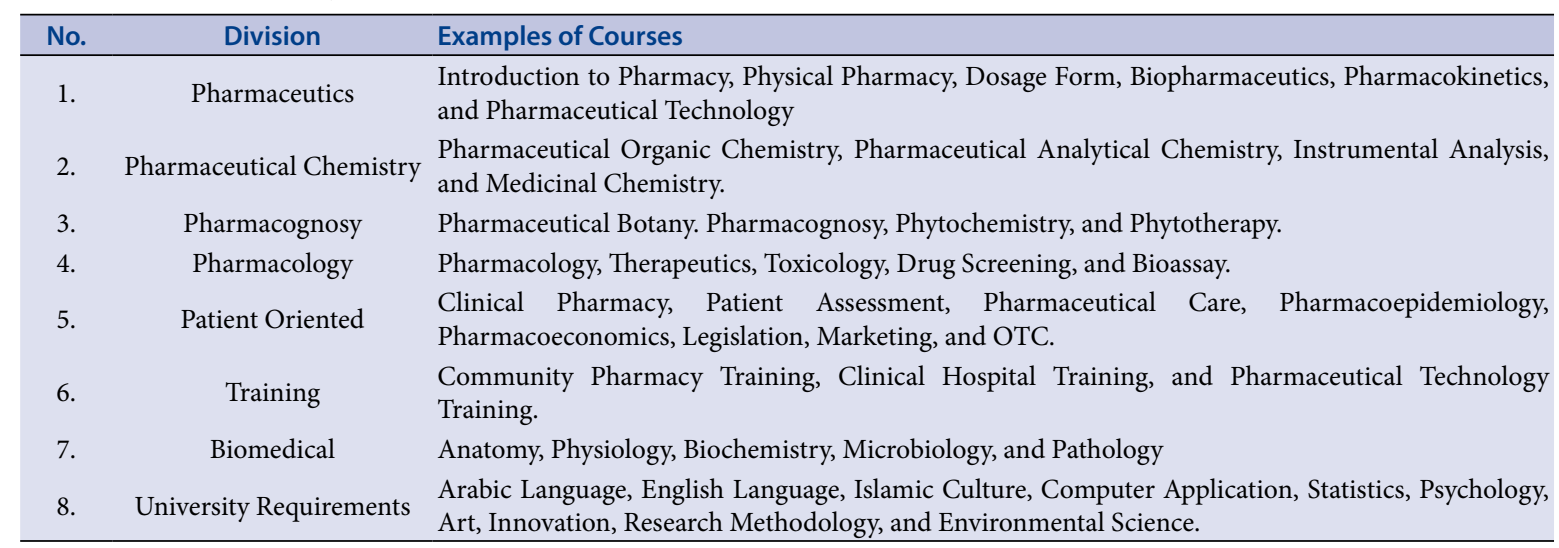

Table 2: Analysis of B. Pharm. Curricula in UAE.

\begin{tabular}{|c|c|c|c|c|c|c|c|c|c|}
\hline \multirow{2}{*}{ B. Pharm. University } & \multicolumn{9}{|c|}{ Credit Hours / Percentage } \\
\hline & Ceut & Chem & $\operatorname{Cog}$ & Col & Pat & $\mathrm{Bm}$ & $\operatorname{Tr}$ & UR & Tot \\
\hline \multirow{2}{*}{$\begin{array}{l}\text { University of Science and Technology of Fujairah } \\
\text { (USTF) }\end{array}$} & 25.0 & 24.0 & 14.0 & 12.0 & 14.0 & 19.0 & 18.0 & 24.0 & 150.0 \\
\hline & 16.7 & 16.0 & 9.3 & 8.0 & 9.3 & 12.7 & 12.0 & 16.0 & 100 \\
\hline \multirow{2}{*}{ Ajman University } & 24.0 & 17.0 & 6.0 & 19.0 & 28.0 & 18.0 & 18.0 & 30.0 & 160.0 \\
\hline & 15.0 & 10.6 & 3.8 & 11.9 & 17.5 & 11.3 & 11.3 & 18.8 & 100 \\
\hline University of Sharjah & 26.0 & 22.0 & 4.0 & 15.0 & 40.0 & 16.0 & 20.0 & 27.0 & 170.0 \\
\hline \multirow{2}{*}{ Dubai Pharmacy College } & 22.0 & 27.0 & 13.0 & 21.0 & 33.0 & 17.0 & 18.0 & 17.0 & 168.0 \\
\hline & 13.1 & 16.1 & 7.7 & 12.5 & 19.6 & 10.1 & 10.7 & 10.1 & 100 \\
\hline \multirow{2}{*}{ RAK Medical and Health Sciences University } & 32.0 & 28.0 & 3.0 & 16.0 & 19.0 & 11.0 & 15.0 & 21.0 & 145.0 \\
\hline & 22.1 & 19.3 & 2.1 & 11.0 & 13.1 & 7.6 & 10.3 & 14.5 & 100 \\
\hline \multirow{2}{*}{ Al-Ain University of Science and Technology } & 13.0 & 18.0 & 5.0 & 10.0 & 41.0 & 22.0 & 21.0 & 30.0 & 160.0 \\
\hline & 8.1 & 11.3 & 3.1 & 6.3 & 25.6 & 13.8 & 13.1 & 18.8 & 100 \\
\hline Average & 15.0 & 14.4 & 4.7 & 9.7 & 18.1 & 10.8 & 11.5 & 15.7 & 100 \\
\hline
\end{tabular}

Ceut: Pharmaceutics, Chem: Pharm. Chemistry, Cog: Pharmacognosy, Col: Pharmacology, Pat: Patient Oriented, Bm: Biomedical, Tr: Training, UR: University Requirements, Tot: Total. 
these universities, study duration is five years and range from 160-265 credit hours (Table 4). These universities represent other Arab countries than the Gulf countries.

\section{RESULTS}

\section{Percentage distribution of $\mathrm{B}$. Pharm divisions}

The average percentage distribution of $\mathrm{B}$. Pharm divisions from UAE study plans was as follows: Pharmaceutics 15\%; Pharm. Chemistry 14.4\%; Pharmacognosy 4.7\%; Pharmacology 9.7\%; Patient-oriented 18.1\%; Biomedical 10.8\%; Training 11.5\%; University Requirements 15.7 (Table 2).

The average percentage distribution of B. Pharm divisions from African universities study plans was as follows: Pharmaceutics $14.4 \%$; Pharm. Chemistry 14.4\%; Pharmacognosy 8.9\%; Pharmacology 8.6\%; Patient-oriented 21.7\%; Biomedical 16.7\%; Training 3.5\%; University Requirements $11.8 \%$. (Table 3).

The average percentage distribution of B. Pharm divisions from Middle Eastern study plans was as follows: Pharmaceutics $12.8 \%$; Pharm. Chemistry 17.7\%; Pharmacognosy 8.6\%; Pharmacology 8.1\%; Patient-oriented 17.1\%; Biomedical 19.9\%; Training 3.6\%; University Requirements 11.6\%. (Table 4).

Comparative study of credit hours between pharmacognosy and patient-oriented courses from UAE universities

The comparative credit hours between Pharmacognosy and PatientOriented courses of UAE Universities are represented in Figure 1. Data used were obtained from percentage of relative divisions shown in Table 2.
Comparative study of credit hours between pharmacognosy and patient-oriented courses of different regions

The comparative credit hours between Pharmacognosy and PatientOriented courses of different regions are represented in Figure 2. Data used was obtained from the average percentage of divisions shown in Tables 2-4.

Comparative study of credit hours between pharmacognosy and biomedical courses from UAE universities

The comparative credit hours between Pharmacognosy and Biomedical courses from UAE Universities are represented in Figure 3. Data used were obtained from percentage divisions shown in Table 2.

Comparative study of credit hours between pharmacognosy and biomedical courses from different regions

The comparative credit hours between Pharmacognosy and Biomedical courses of Universities from different regions are represented in Figure 4. Data used were obtained from the average percentage divisions shown in Tables 2-4.

\section{Comparative analysis of B. Pharm curricula from different regions}

The comparative credit hours allotted to all divisions of B. Pharm curricula from studied universities are represented in Figure 5. Data used were obtained from the average percentage divisions shown in Tables 2-4.

Table 3: Analysis of B. Pharm. Curricula in Africa.

\begin{tabular}{|c|c|c|c|c|c|c|c|c|c|}
\hline \multirow{2}{*}{ B. Pharm. University } & \multicolumn{9}{|c|}{ Credit Hours / Percentage } \\
\hline & Ceut & Chem & Cog & Col & Pat & $\mathrm{Bm}$ & $\mathrm{Tr}$ & UR & Tot \\
\hline \multirow{2}{*}{ University of Khartoum } & 29.0 & 35.0 & 21.0 & 18.0 & 26.0 & 35.0 & 6.0 & 18.0 & 188.0 \\
\hline & 15.4 & 18.6 & 11.2 & 9.6 & 13.8 & 18.6 & 3.2 & 9.6 & 100 \\
\hline \multirow{2}{*}{$\begin{array}{l}\text { Madonna University } \\
\text { (Nigeria) }\end{array}$} & 31.0 & 25.0 & 19.0 & 22.0 & 26.0 & 38.0 & 5.0 & 40.0 & 206.0 \\
\hline & 15.0 & 12.1 & 9.2 & 10.7 & 12.6 & 18.4 & 2.4 & 19.4 & 100 \\
\hline \multirow{2}{*}{ Addis- Ababa University } & 39.0 & 39.0 & 20.0 & 17.0 & 120.0 & 40.0 & 15.0 & 20.0 & 310.0 \\
\hline & 12.6 & 12.6 & 6.5 & 5.5 & 38.7 & 12.9 & 4.8 & 6.5 & 100 \\
\hline \multirow{2}{*}{ Average } & 33.0 & 33.0 & 20.0 & 19.0 & 57.3 & 37.7 & 8.7 & 26.0 & 234.7 \\
\hline & 14.4 & 14.4 & 8.9 & 8.6 & 21.7 & 16.7 & 3.5 & 11.8 & 100 \\
\hline
\end{tabular}

Ceut: Pharmaceutics, Chem: Pharm. Chemistry, Cog: Pharmacognosy, Col: Pharmacology, Pat: Patient Oriented, Bm: Biomedical, Tr: Training, UR: University Requirements, Tot: Total.

Table 4: Analysis of B. Pharm. Curricula in Middle East.

\begin{tabular}{|c|c|c|c|c|c|c|c|c|c|}
\hline \multirow{2}{*}{ B. Pharm. University } & \multicolumn{9}{|c|}{ Credit Hours / Percentage } \\
\hline & Ceut & Chem & $\operatorname{Cog}$ & Col & Pat & $\mathrm{Bm}$ & $\operatorname{Tr}$ & UR & Tot \\
\hline \multirow{2}{*}{$\begin{array}{l}\text { Cairo University } \\
\text { (Egypt) }\end{array}$} & 17.0 & 32.0 & 21.0 & 28.0 & 39.0 & 37.0 & 3.0 & 15.0 & 192.0 \\
\hline & 8.9 & 16.7 & 10.9 & 14.6 & 20.3 & 19.3 & 1.6 & 7.8 & 100 \\
\hline \multirow{2}{*}{$\begin{array}{l}\text { Al- Baath University } \\
\text { (Syria) }\end{array}$} & 34.0 & 54.0 & 23.0 & 17.0 & 26.0 & 69.0 & 2.0 & 40.0 & 265.0 \\
\hline & 12.8 & 20.4 & 8.7 & 6.4 & 9.8 & 26.0 & 0.8 & 15.1 & 100 \\
\hline \multirow{2}{*}{$\begin{array}{l}\text { Beirut Arab University } \\
\text { (Lebanon) }\end{array}$} & 15.0 & 35.0 & 15.0 & 9.0 & 51.0 & 21.0 & 22.0 & 12.0 & 180.0 \\
\hline & 8.3 & 19.4 & 8.3 & 5.0 & 28.3 & 11.7 & 12.2 & 6.7 & 100 \\
\hline \multirow{2}{*}{$\begin{array}{l}\text { Amman Arab University } \\
\text { (Jordan) }\end{array}$} & 34.0 & 23.0 & 10.0 & 10.0 & 20.0 & 36.0 & 0.0 & 27.0 & 160.0 \\
\hline & 21.3 & 14.4 & 6.3 & 6.3 & 12.5 & 22.5 & 0.0 & 16.9 & 100 \\
\hline \multirow{2}{*}{ Average } & 25.0 & 36.0 & 17.3 & 16.0 & 34.0 & 40.8 & 6.8 & 23.5 & 199.3 \\
\hline & 12.8 & 17.7 & 8.6 & 8.1 & 17.7 & 19.9 & 3.6 & 11.6 & 100 \\
\hline
\end{tabular}

Ceut: Pharmaceutics, Chem: Pharm. Chemistry, Cog: Pharmacognosy, Col: Pharmacology, Pat: Patient Oriented, Bm: Biomedical, Tr: Training, UR: University Requirements, Tot: Total. 


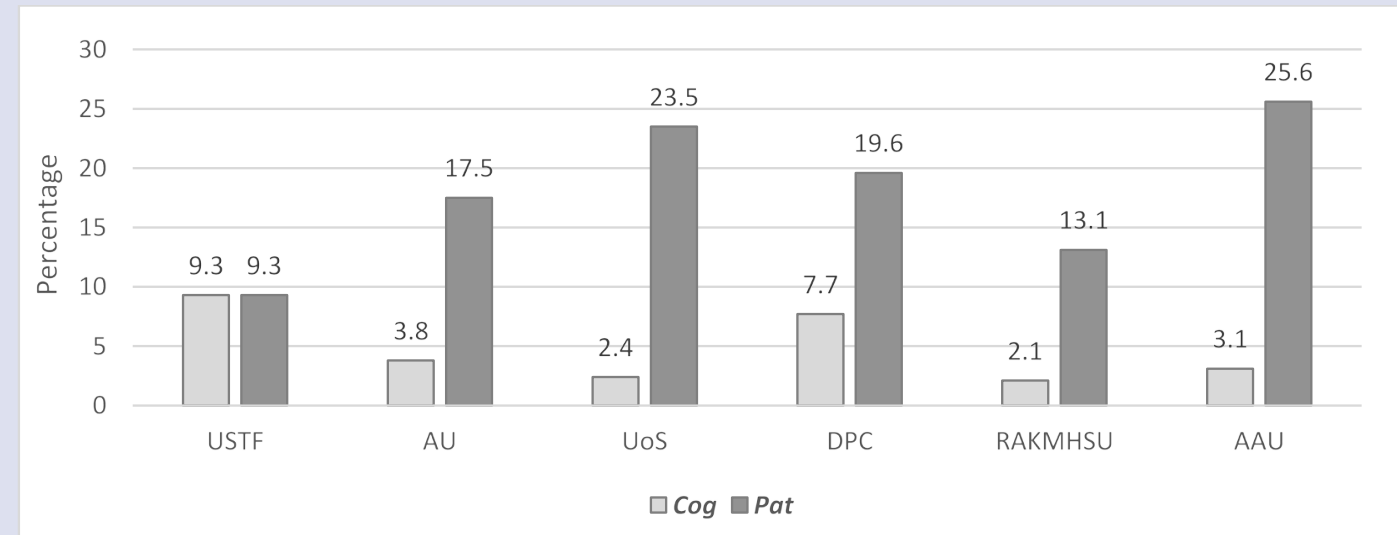

Figure 1: Comparative Credit Hours between Pharmacognosy and Patient Oriented Courses from UAE Universities. USTF: University of Science and Technology of Fujairah, AU: Ajman University, UoS: University of Sharjah, DPC: Dubai Pharmacy College, RAKMHSU: RAK Medical and Health Sciences University, AAU: Al Ain University.

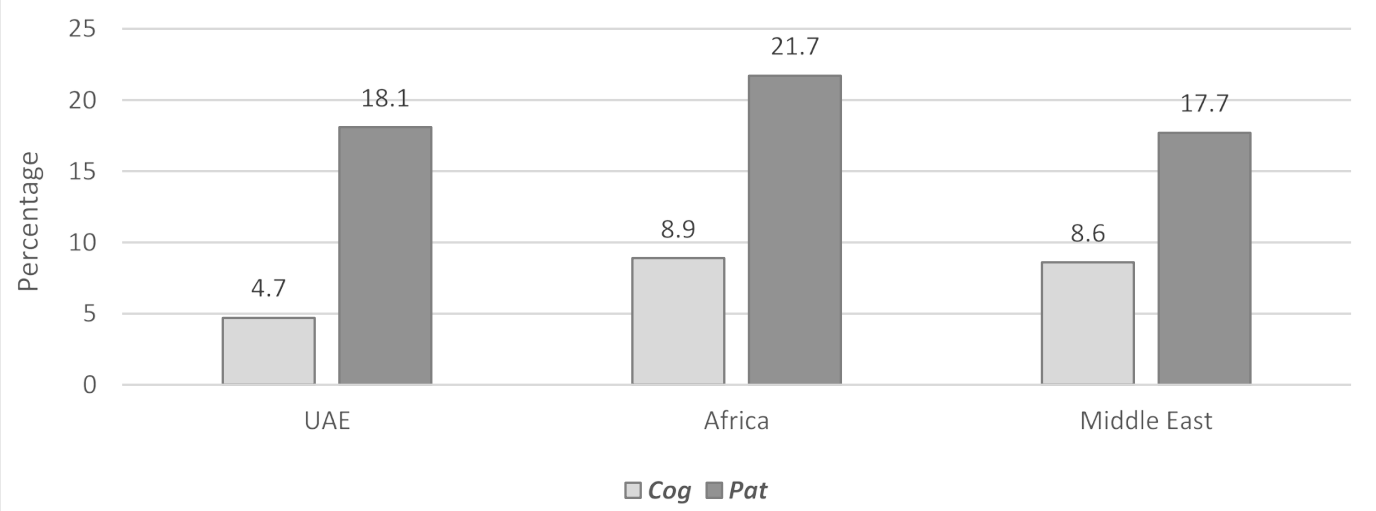

Figure 2: Comparative Credit Hours between Pharmacognosy and Patient Oriented Courses of Different Regions.

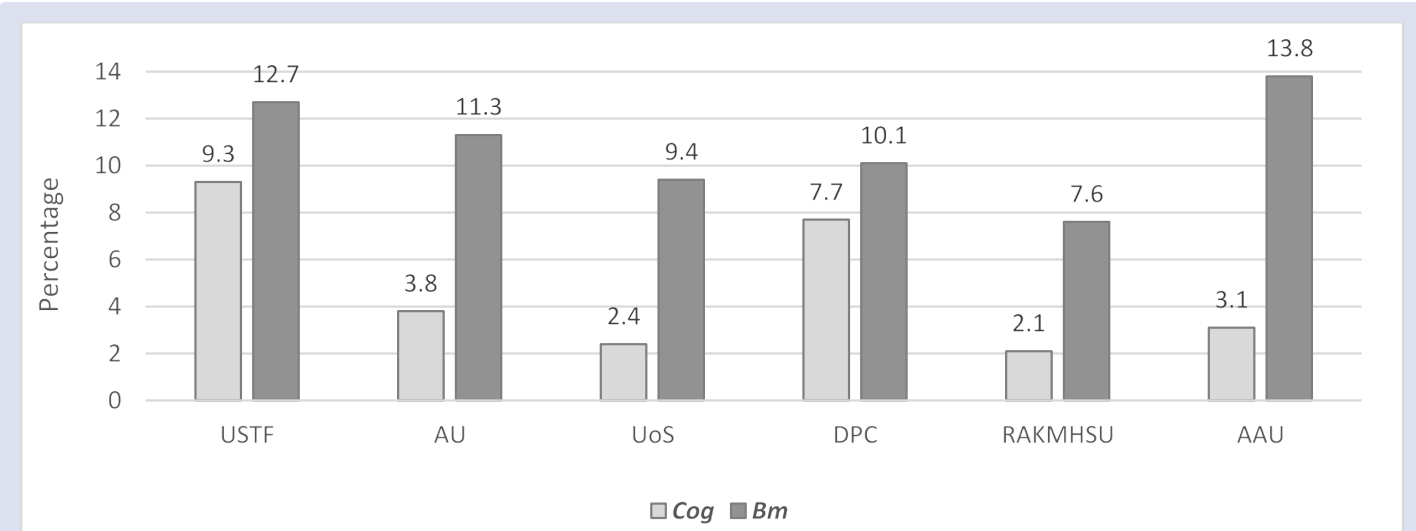

Figure 3: Comparative Credit Hours between Pharmacognosy and Biomedical Courses from UAE Universities. USTF: University of Science and Technology of Fujairah, AU: Ajman University, UoS: University of Sharjah, DPC: Dubai Pharmacy College, RAKMHSU: RAK Medical and Health Sciences University, AAU: Al Ain University. 


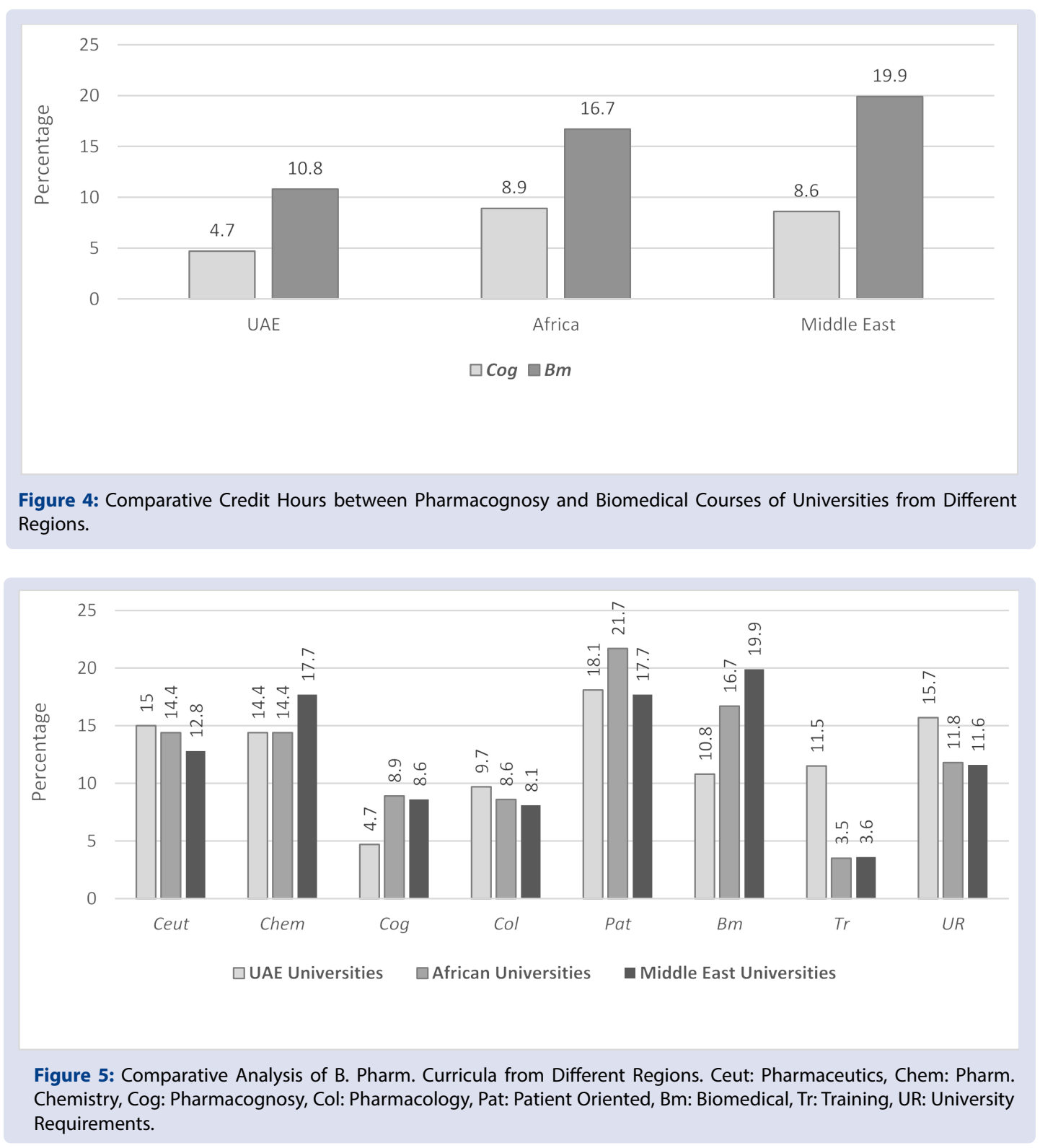

\section{DISCUSSION}

Current B. Pharm Curricula in some developing countries aimed at increasing Patient-oriented courses for Pharmacy graduates. There is no doubt that this is beneficial for the development of the performance of Pharmacy graduates towards the requirements of their jobs in respective countries. This reflected on decreasing credit hours allotted to Pharmacognosy courses in B Pharm curricula of the studied countries, though Pharmacognosy is one of the main Pharmaceutical Sciences of the B. Pharm programmes in the past. In 2018 Shandal and co-workers ${ }^{7}$ studied this issue. To our knowledge no other workers reported on that issue.

Present results of current B. Pharm. Curricula of UAE universities revealed relatively low credit hours allotted to Pharmacognosy courses (4.7\%) of the study plans as compared to Patient - oriented courses (18.1\%). This is illustrated in Table 2 and Figure 2. That reveals the Current B. Pharm Curricula focus on developing Patient-oriented courses at the expense of Pharmacognosy. Yet, the clinical pharmacy practice in these countries is still under developed. ${ }^{3}$ Such a trend is practiced in all Gulf countries. An exception of UAE universities, is USTF which maintained the same percentage of credit hours to both Pharmacognosy and Patient-oriented courses (9.3\%) Figure 1.
The same above pattern of UAE universities is also reflected on the studied representative universities from Africa and Middle East. Some keep nearly balanced distribution between Pharmacognosy and Patient-oriented courses and others show big differences between the two. University of Khartoum from Africa show balanced distribution: Pharmacognosy courses (11.2\%) and Patient - oriented courses (13.8\%). Table 3. Al-Bath University from Middle East: Pharmacognosy courses (8.7\%) and Patient - oriented courses (9.8\%). Table 4. On the other hand some universities reflected a big difference between the two courses. Addis-Ababa University from Africa: Pharmacognosy courses (6.5\%) and Patient - oriented courses (38.7\%). Table 3. Beirut Arab University from Middle East: Pharmacognosy courses (8.3\%) and Patient - oriented courses (28.3\%). Table 4 . The differences in average percentage between Pharmacognosy and Patient-oriented courses in these regions is nearly the same as in UAE universities, an average of low credit hours allotted to Pharmacognosy and relatively high credit hours allotted to Patient-oriented courses, Figure 2. African universities: Pharmacognosy courses (8.9\%) and Patient - oriented courses (21.7\%). Middle East universities: Pharmacognosy courses (8.6\%) and Patient oriented courses (17.7). Yet the credit hours affected to pharmacognosy courses in both Africa (8.9\%) and the Middle East (8.6\%) are higher than that of UAE (4.7\%). 
Other big difference in average credit hours is between Pharmacognosy and Biomedical courses. The big difference between average credit hours allotted to Pharmacognosy and Biomedical courses in UAE universities is represented in Figure 3. As seen all UAE universities show big difference between the two courses with the exception of USTF and Dubai Pharmacy College. The big difference is reflected in all three regions, Figure 4. UAE: Pharmacognosy courses $(4.7 \%)$ and Biomedical courses (10.8\%). Africa: Pharmacognosy courses $(8.9 \%)$ and Biomedical courses (16.7\%). Middle East: Pharmacognosy courses (8.6\%) and Biomedical courses (19.9\%).

Figure 5 reflects the low credit hours allotted to both Pharmacognosy and Pharmacology courses compared with other Pharmaceutical Sciences in countries of all the three regions studied. In these countries, Patient-oriented, Biomedical, and University Requirement courses have relatively higher credit hours than other courses of the B. Pharm programme. This revealed how some basic sciences of Pharmaceutical Education were affected due to Current B. Pharm. Curricula, which may lead to adverse effects on the performance of Pharmacy graduates in this field while practicing their job. All studied universities offer relatively high credit hours for Patient-Oriented, Biomedical and University Requirements as compared with the major Pharmaceutical Sciences

\section{CONCLUSION}

After analyzing the current B. Pharm Curricula in studied countries, it is clear that there is an insufficient number of credit hours allotted to Pharmacognosy knowledge at the university level, especially in UAE universities. This coincides with the findings of Shandal and coworkers. ${ }^{7}$ It may substantially affect the understanding of graduates of Pharmacy towards Herbal Drug use, side effects, and Herb-Drug interaction necessary for Patient care within the Health Care System. It may affect the discovery and development of medicinal drugs from herbs in these countries. It may retard research and development of Herbalism, which results in a drawback on the promotion of Health in rural areas. This adverse impact was not reported by other authors.

\section{RECOMMENDATIONS}

To ensure the continuous progress of Pharmacognosy education and its support to Drug Discovery Health Care System as well as Research and Development of Herbalism, it is recommended to balance credit hours allotted to Pharmacognosy courses in study plans of developing countries. These additional credit hours may be deducted from Biomedical or University Requirements courses. New advanced courses to B. Pharm curricula, such as Phytoyherpy, Phytopharmaceutics, Herbal Therapy and Natural Medicine may be included. Conferences by Colleges of Pharmacy in developing countries to discuss the issue of decreasing credit hours allotted to Pharmacognosy within the B. Pharm Curricula may be organized.

There is an urgent need to advance the practice of Herbalism. Therefore, it is recommended to initiate Conferences on Herbalism and establish Herbalism Institutes and Herbal Drug Pharmacy under the direction of the Ministry of Health in developing countries.

\section{ACKNOWLEDGMENT}

The author acknowledges the assistance of Teaching Assistant Staff: 1Mr. Nader A. H. Abu-Mukhaimer for designing tables and figures, 2Mr. Tarek Shahin for editing the manuscript.

\section{REFERENCES}

1. Sarker DS. Pharmacognosy in modern pharmacy curricula. Pharmacgnosy Magazine. 2012;8(30):91-2.

2. Orhan IE. Pharmacognosy: Science of natural products in drug discovery Bioimpacts. 2014;4(3):109-10

3. Gullo V, Mcalpine J, Baker D. Drug discovery from natural products. Journal of Industrial Microbiology and Biotechnology. 2006;33(7):523-31.

4. Zhang J, Onakpoya IJ, Posadzki P, Eddouks M. The Safety of Herbal Medicine: From prejudice to evidence. Evidence-Based Complementary and Alternative Medicine. 2015;3.

5. Hussain A, Malik M, Abdullah S. Review of evolving trend in clinical evidence pharmacy. American Journal of Pharmacological Sciences. 2017;5(1):1-7.

6. Khan T M, Anwar M. Ahmed K K M. A prospective for clinical pharmacy curriculum development and validation in Asian developing nations. J Young Pharma. 2011;3(2):151-4.

7. Shandal IMAF, Mohamed SS, Qarawi MA. Pharmacognosy and new trends of B. Pharm curricula. International Journal of Current Pharmaceutical Research. 2018;10(6):25-9.

8. College of Pharmacy and Health Sciences, University of Science and Technology of Fujairah. [Cited 2019 Jan]. Available from: http://www.ustf.ac.ae/ en/pharmacy.html

9. College of Pharmacy and Health Sciences, Ajman University. [Cited 2019 Jan] Available from: https://www.ajman.ac.ae/en/pharmacy.htm

10. Faculty of Pharmacy, University of Sharjah. [Cited 2019 Jan]. Available from: http://www.sharjah.ac.ae/en/academics/Colleges/Pharmacy/Pages/

11. Dubai Pharmacy College. [Cited 2019 Jan]. Available from: http://www.dpc.edu/ academics.php

12. RAK Medical and Health Sciences University. [Cited 2019 Jan]. Available from: http:// www.rakmhsu.com/medical courses-in-uae

13. Faculty of Pharmacy, Al-Ain University. [Cited 2019 Jan]. Available from: https:// pharmacy.aau.ac.ae/en/programmes

14. Faculty of Pharmacy, Khartoum University. [Cited 2019 Jan]. Available from: https://pharm.uofk.edu/index.php/en

15. Faculty of Pharmaceutical Sciences, Madonna University. [Cited 2019 Jan] Available from: http://madonnauniversity.edu.ng/Pharmacy\%20Faculty.html

16. Faculty of Pharmacy, Addis-Ababa University. [Cited 2019 Jan]. Available from: https://portal.aau.edu.et/Web/ProgrammeList

17. Faculty of Pharmacy, Cairo University. [Cited 2019 Jan]. Available from: https:// www.pharma.cu.edu.eg/English/AcademicProgrammes/UgProgrammes/ Regular/

18. Faculty of Pharmacy, Al-Baath University. [Cited 2019 Jan]. Available from: http://pharmacy.albaath-univ.edu.sy/

19. Faculty of Pharmacy, Beirut Arab University. [Cited 2019 Jan]. Available from: https://www.bau.edu.lb/Programme/Pharmacy/Bachelor/Pharmacy

20. Faculty of Pharmacy, Amman Arab University. [Cited 2019 Jan]. Available from: http://www.just.edu.jo/FacultiesandDepartments/FacultyofPharmacy/ 


\section{SUMMARY}

This paper studied the study plans of B. Pharm Programme of thirteen (13) universities from UAE, Africa, and the Middle East. The study of Study Plans revealed relatively low credit hours allotted to pharmacognosy courses as compared to Patient - Oriented, Biomedical and University Requirements courses. This may have adverse effect on Drug Discovery, Health care system, and Herbalism.

\section{ABOUT AUTHORS}

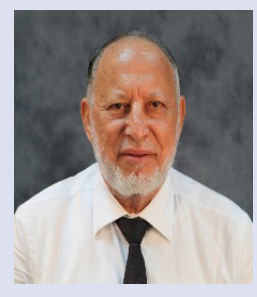

Dr. I. M. Abu-Al-Futuh is an Associate Professor of Pharmacognosy at the College of Pharmacy and Health Sciences, University of Science and Technology of Fujairah. He has contributions in the fields of Pharmacognosy Teaching, Research, Consultation and Industry. His contribution to the above fields of pharmacy and related sciences are documented by published scientific articles in journals, Chapter in a Book, and a UNIDO Report on Industrial Utilization of Medicinal Plants. He Presented some Papers in International Conferences.

Cite this article: Abu-Al-Futuh IM. Study on Pharmacognosy Curricula in UAE B. Pharm Programmes and Possible Implications. Pharmacogn J. 2020;12(3):478-84. 